\title{
Hydrodynamic Analysis of Electrochemical Cells
}

\author{
Cesar Augusto Real-Ramirez and Jesus Isidro Gonzalez-Trejo \\ Universidad Autonoma Metropolitana - Azcapotzalco \\ Mexico
}

\section{Introduction}

The systems in which an electrode immersed in a solution causes a chemical reaction have been studied for over a hundred years. It has long been known that the behavior of these systems is determined by two main factors: the rate with which the substance comes into contact with the electrode and the rate of the electrochemical reactions at the electrode.

During the first four decades of the twentieth century, many works were devoted to this subject; however, most of them were experimental works. Those works found that the limiting current increases with increasing the rate of stirring (Bircumshaw \& Riddiford, 1952). Usually, the results were expressed by means of a power relation of the form:

$$
j_{\lim } \propto \omega^{a}
$$

where $j_{\lim }$ is the limiting current, $\omega$ is the rotation speed and $a$ is the power such that $0<a \leq 1$.

The earliest theoretical studies of electrochemical cells with a rotating disk were reported by Nernst (Nernst, 1904; Nernst \& Merriam, 1905). In that works, Nernst introduced the concept of diffusion layer. According to Nernst, the thickness of the diffusion layer is extremely small and the movement of fluid within it may be neglected.

In 1932, Eucken (Eucken, 1932) presented another theoretical study of electrochemical cells. The aim of that work was to provide an exact hydrodynamics theory of the diffusion towards a plane electrode submerged in a solution moving with a relatively high velocity.

Following a similar approach to that employed by Eucken, Levich (Levich, 1942) presented a theory describing accurately the hydrodynamics generated by an electrode with the shape of a flat disk of a sufficiently large area, rotating about an axis perpendicular to the plane of the disc with a constant angular velocity. The theory of Levich is restricted to the case of sufficiently small Reynolds numbers, so that the motion of the fluid might be considered as laminar. Levich used the transformation proposed by von Kármán (von Kármán, 1921), which allows writing the Navier-Stokes equations as a system of ordinary differential equations. Levich also used the solution proposed by Cochran (Cochran, 1934) to the resulting system of ordinary differential equations.

Although the theory developed by Levich was in a good agreement with most experimental results reported previously, at the end of his work Levich pointed out that: “... a precise experimental study of the phenomena of concentration polarization in a wide range of 
Reynolds numbers and simple geometrical conditions, allowing to establish decisively the quantitative agreement between the theory and the experiment, is highly desirable" (Levich, 1942).

Several authors have analyzed experimentally some of the geometrical features of systems typically used in electrochemical studies in order to verify if these systems meet the basic theoretical requirements of the Levich theory.

The electrode shape, the electrode immersion depth and the cell volume were considered among the main sources of discrepancy between ideal and existent experimental systems. In accordance with Riddiford (Riddiford, 1966), a cylindrical shape for the electrode promotes an adverse fluid flow pattern and other electrode shapes should be used instead. Azim and Riddiford (Azim \& Riddiford, 1962) recommended conical or bell-shaped electrode designs. The effect of the electrode shape upon the rate of mass transfer was widely analyzed by Blurton and Riddiford (Blurton \& Riddiford, 1965) and by Prater and Adams (Prater \& Adams, 1966). However, in accordance with Prater and Adams: “... the difficulty of fabricating the bell-shaped electrode probably outweighs its advantages...".

Prater and Adams (Prater \& Adams, 1966) also studied the effect of electrode immersion depth upon limiting currents, but only a bell-shaped electrode was employed. In accordance with these authors: "... identical results may be obtained whether the electrode is immersed to a depth of $1.85 \mathrm{~cm}$. or barely touching the solution...".

An accurate experimental determination of the velocity field near the electrode becomes difficult due to cell geometry and electrode dimensions. This task is hard to accomplish even using modern non-intrusive techniques such as Particle Imaging Velocimetry (PIV). Nevertheless, recently the flow field inside a confined electrochemical cell configuration was measured through Laser Doppler Anemometry (Mandin, Pauporte, Fanouillere, \& Lincot, 2004).

Another alternative to obtain an accurate approximation of the velocity and pressure profiles due to a rotating disk electrode is to use the Computer Fluid Dynamics (CFD) technique in which, the three-dimensional Navier-Stokes equations are solved numerically.

The aim of this chapter is to review some of the works recently published in which the CFD technique has been used to characterize the hydrodynamic behavior of the liquid inside electrochemical cells with a rotating disk electrode (RDE). This chapter also discusses the assumptions stated in the revised works as well as the accurateness of their results. In addition, this paper discusses some of the implications of the results obtained with the CFD technique on the geometric characteristics of the electrochemical cell, the electrode geometry and the operating conditions.

This chapter is organized as follows. The properties as well as the main features of the ideal system considered in the theory developed by Levich (Levich, 1942) are discussed in Section 2. This section also presents a comparison between two approximate solutions to the problem stated by von Kármán (von Kármán, 1921). The main features of several works recently published in which the CFD technique has been used to characterize the hydrodynamics of electrochemical cells with a RDE are presented in Section 3. Based on the results obtained with CFD technique, Section 4 discusses some simple modifications that can be implemented in electrochemical cells that can significantly improve the accuracy of measurements made on these devices. 


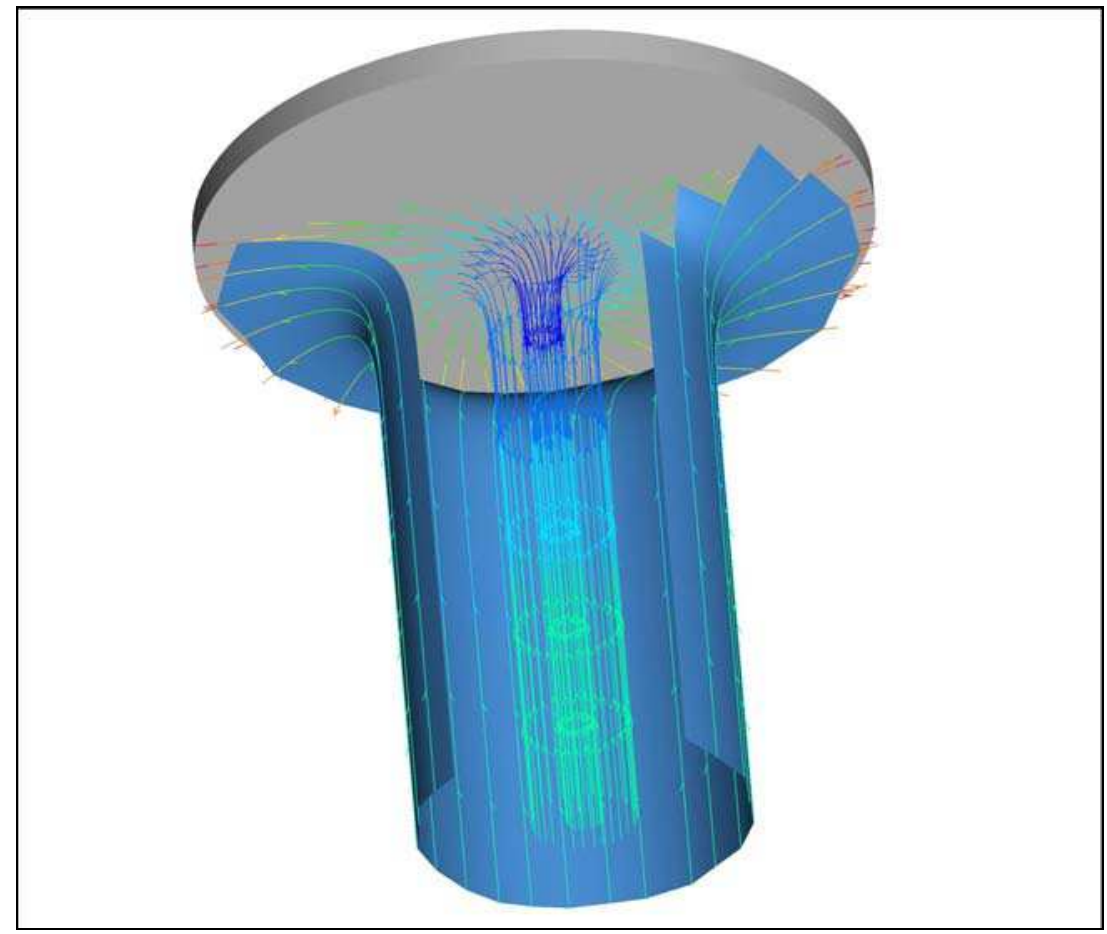

Fig. 1. Typical fluid flow pattern of the ideal system.

\section{Ideal system model}

\subsection{System description}

In the model of the ideal system considered by Levich (Levich, 1942), the analytical expressions describing the hydrodynamic behavior of the fluid in the vicinity of the electrode active surface is in accordance with the behavior described by von Kármán (von Kármán, 1921). Levich considered that the fluid velocity field inside the cell can be modeled as the steady-state motion of an incompressible Newtonian viscous fluid due to an infinite rotating plane disk whose thickness is equal to zero. A system like this was originally proposed by von Kármán (von Kármán, 1921). This model assumes that the fluid density and viscosity remain constant. Additionally, the fluid is infinite in extent and is located above the disc.

Figure 1 shows the typical fluid flow pattern of the ideal system. To create this figure, a small value for the electrode rotation speed was employed. Several stream lines were included in this figure. The stream lines were colored in accordance with its radius value. Given that the rotating disc acts as a centrifugal fan, the fluid moves radially outwards near the disc. Therefore, to preserve continuity, an axial motion towards the lamina is generated (Cochran, 1934). Figure 1 shows that far from the disk the radial and angular velocity components are zero. On the contrary, near the disk, the behaviour of the fluid resembles logarithmic spirals. Figure 2 shows the fluid velocity field on a plane parallel to the disk. This figure also shows that a stagnation point is formed at the center of the disk. 


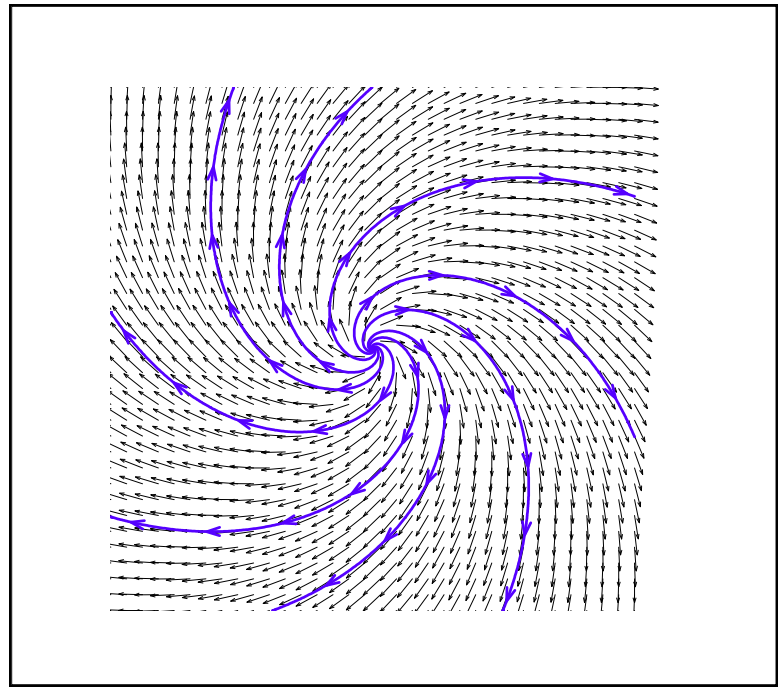

Fig. 2. Fluid velocity field on a plane parallel to the disk which resembles logarithmic spirals.

\subsection{Mathematical equations}

The mathematical equations of the ideal model are the continuity and the Navier-Stokes equations in cylindrical coordinates at the steady-state:

$$
\begin{gathered}
u+r \frac{\partial u}{\partial r}+r \frac{\partial w}{\partial z}=0 \\
u \frac{\partial u}{\partial r}-\frac{v^{2}}{r}+w \frac{\partial u}{\partial z}=-\frac{1}{\rho} \frac{\partial p}{\partial r}+v\left\{\frac{\partial^{2} u}{\partial r^{2}}+\frac{\partial}{\partial r}\left(\frac{u}{r}\right)+\frac{\partial^{2} u}{\partial z^{2}}\right\} \\
u \frac{\partial v}{\partial r}-\frac{u v}{r}+w \frac{\partial v}{\partial z}=v\left\{\frac{\partial^{2} v}{\partial r^{2}}+\frac{\partial}{\partial r}\left(\frac{v}{r}\right)+\frac{\partial^{2} v}{\partial z^{2}}\right\} \\
u \frac{\partial w}{\partial r}+w \frac{\partial w}{\partial z}=-\frac{1}{\rho} \frac{\partial p}{\partial z}+v\left\{\frac{\partial^{2} w}{\partial r^{2}}+\frac{1}{r} \frac{\partial w}{\partial r}+\frac{\partial^{2} w}{\partial z^{2}}\right\}
\end{gathered}
$$

This model assumes that the fluid flow pattern is axisymmetric respect the axial axis. In this equations, $r$ and $z$ are the radial and axial coordinates, $p$ is the pressure, $\rho$ is the density of the fluid and $\mathrm{v}$ is the kinematic viscosity of the fluid. In (2) and (3), $u, v$ and $w$ are the radial, the angular and the axial velocity components respectively. This model also assumes that the flow regime is laminar.

The boundary conditions for (2) and (3) are as follows: At the disc surface $(z=0)$, a non-slip condition is assumed, that is, $u=0, w=0$ and $v=\omega r$, where $\omega$ is the electrode rotation speed. Far from the disc $(z \rightarrow \infty)$, it is assumed that there is no flow in the radial and the angular directions, which can be expressed as $u=0$ and $v=0$. In addition, the axial velocity reaches its limiting velocity $U_{0}$, that is, $w=U_{0}$. 


\subsection{Approximate solutions}

von Kármán (von Kármán, 1921), introduced the following dimensionless independent (Equation 4) and dependent variables (Equation 5):

$$
\begin{gathered}
\xi=z \sqrt{\frac{\omega}{v}} \\
F(\xi)=\frac{u}{r \omega}, G(\xi)=\frac{v}{r \omega}, H(\xi)=\frac{w}{\sqrt{v \omega}} \text { and } P(\xi)=\frac{p}{\rho v \omega}
\end{gathered}
$$

After applying the variable change, Equations (2) and (3) can be rewritten as a set of four ordinary differential equations:

$$
\begin{gathered}
2 F+H^{\prime}=0 \\
F^{\prime \prime}-H F^{\prime}-F^{2}+G^{2}=0 \\
G^{\prime \prime}-H G^{\prime}-2 F G=0 \\
H^{\prime \prime}-H H^{\prime}-P^{\prime}=0
\end{gathered}
$$

The boundary conditions for the system are:

$$
H=F=P=0, G=1 \text { at } \xi=0,
$$

and

$$
F=G=0 \text { at } \xi=\infty
$$

Several authors have developed approximate solutions to the equations system (6)-(8) subject to boundary conditions given by Equations (10) and (11). The most famous approximate solution was obtained by Cochran (Cochran, 1934), which is composed by two infinite series, one a power series near the disk and the other a series in exponential functions away from the disk.

The first set of equations is valid only near the $\operatorname{disk}(\xi \rightarrow 0)$ :

$$
\begin{gathered}
F=a \xi-\frac{1}{2} \xi^{2}-\frac{b}{3} \xi^{3}+\cdots \\
G=1+b \xi+\frac{1}{3} a \xi^{3}+\cdots \\
H=-a \xi^{2}+\frac{1}{3} \xi^{3}+\frac{b}{6} \xi^{4}+\cdots
\end{gathered}
$$

The second set is valid far from the $\operatorname{disk}(\xi \rightarrow \infty)$ :

$$
F=A e^{-\alpha \xi}-\frac{\left(A^{2}+B^{2}\right)}{2 \alpha^{2}} e^{-2 \alpha \xi}+\frac{A\left(A^{2}+B^{2}\right)}{4 \alpha^{4}} e^{-3 \alpha \xi}+\cdots
$$




$$
\begin{gathered}
G=B e^{-\alpha \xi}-\frac{B\left(A^{2}+B^{2}\right)}{12 \alpha^{4}} e^{-3 \alpha \xi}+\cdots \\
H=-\alpha+\frac{2 A}{\alpha} e^{-\alpha \xi}-\frac{\left(A^{2}+B^{2}\right)}{2 \alpha^{3}} e^{-2 \alpha \xi}+\frac{A\left(A^{2}+B^{2}\right)}{6 \alpha^{5}} e^{-3 \alpha \xi}+\cdots
\end{gathered}
$$

Where in both sets, $a, b, A, B$ and $\alpha$ are constants.

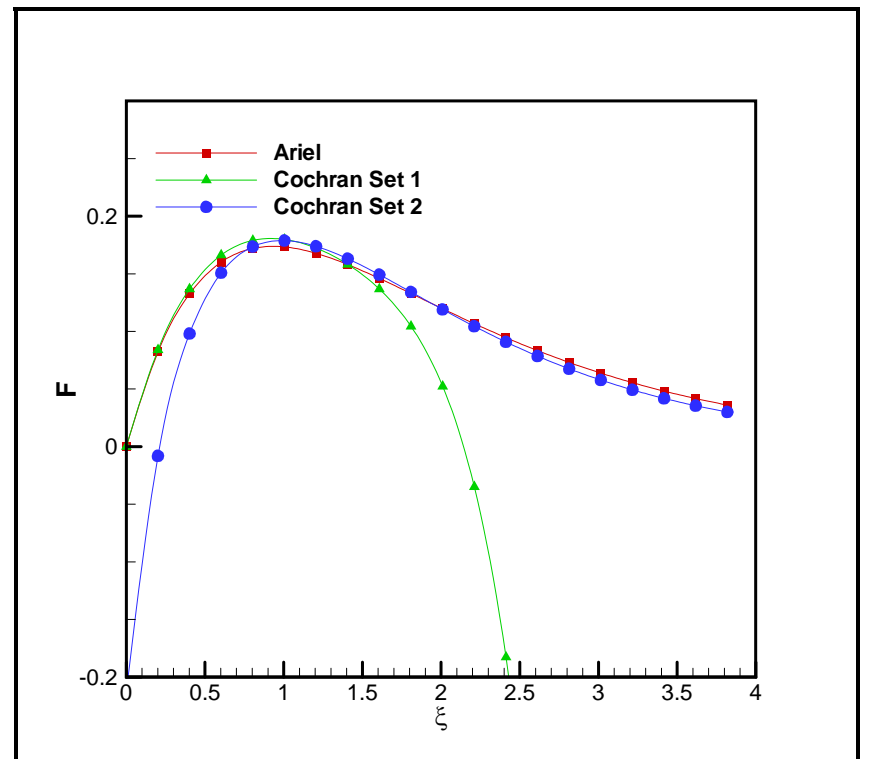

Fig. 3. Comparison of the solutions developed by Cochran and Ariel for the radial velocity component.

Contrary to the approach stated by Cochran, Ackroyd (Ackroyd, 1978) developed a solution composed by only one set of infinite series of exponential terms with negative exponents. Following Arckroy approach, Ariel (Ariel, 1996) presented an approximate solution in which is possible to obtain better results than that obtained with other approximate methods. The solution developed by Ariel is given by the following equations:

$$
\begin{gathered}
F=\beta^{2}\left(\frac{1}{8}\left(2 e^{-\beta \xi}-e^{-2 \beta \xi}\right) \ln \left(\frac{4 e^{\beta \xi}-1}{3}\right)+\frac{1}{2}\left(e^{-\beta \xi}-e^{-2 \beta \xi}\right)\right) \\
G=\frac{1}{3}\left(4 e^{-\beta \xi}-e^{-2 \beta \xi}\right) \\
H=\beta\left(\frac{1}{8}\left(4 e^{-\beta \xi}-e^{-2 \beta \xi}\right) \ln \left(\frac{4 e^{\beta \xi}-1}{3}\right)-\frac{1}{2}\left(2-3 e^{-\beta \xi}+e^{-2 \beta \xi}\right)\right)
\end{gathered}
$$


Where $\xi$ is defined as in Equation (4) and $\beta=0.9130294741$. The main advantage of the solution proposed by Ariel over that obtained by Cochran is that Equations (18)-(20) can be evaluated for any value of $\xi$ such that $0 \leq \xi<\infty$.

Figures 3, 4 and 5 show a comparison of the solutions obtained by Cochran and Ariel for the radial, angular and axial velocity components, respectively. Roughly speaking, these figures show that the first of functions of the solution proposed by Cochran are valid when $\xi \leq 1$. These figures also shows that the trend of the two sets of functions that comprises the solution proposed by Cochran are completely distinct for $\xi \geq 1.5$.

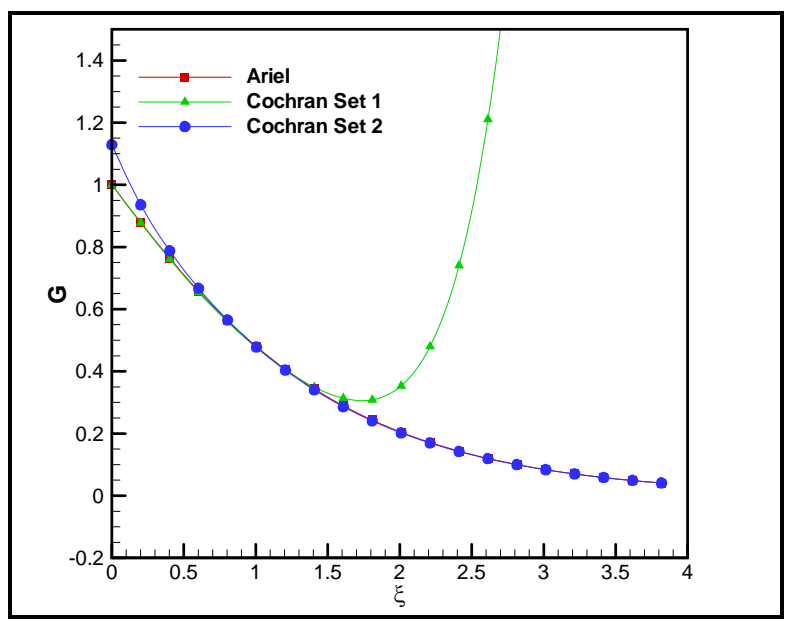

Fig. 4. Comparison of the solutions developed by Cochran and Ariel for the angular velocity component.

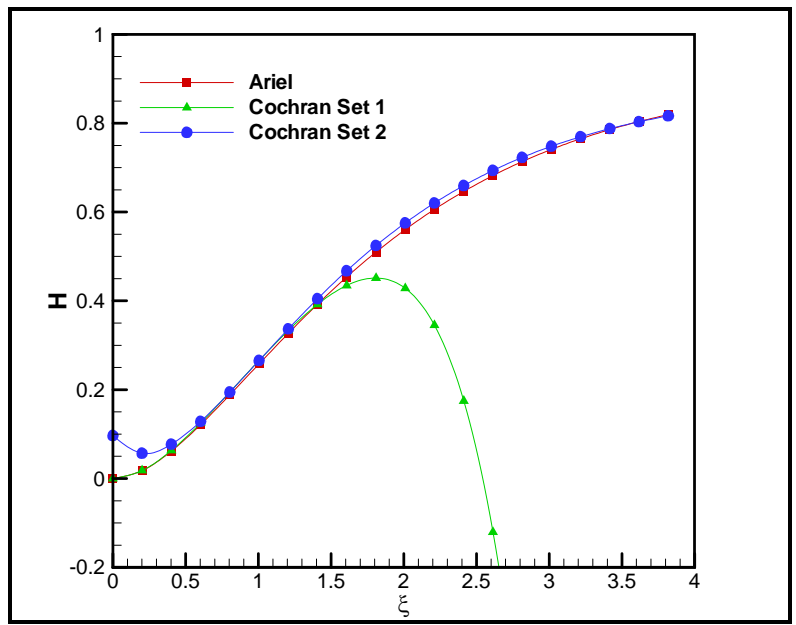

Fig. 5. Comparison of the solutions developed by Cochran and Ariel for the axial velocity component. 
Figures 3, 4 and 5 show that the results of the approximate solutions developed by Cochran and by Ariel are very similar. Volgin and Davydov (Volgin \& Davydov, 2007) shown that the error associated to the available approximate equations to calculate the velocity field range from 1 to $0.01 \%$. In addition, they found that to provide an accuracy of about $0.1 \%$, the length of computational region should be approximately twice the diffusion layer thickness. To reach higher accuracy, the extension of the computational region must be increased.

\section{Simulation with CFD}

Computational Fluid Dynamics (CFD) is a technique that allows generating fluid flow simulations with by means of computers. CFD solves numerically the governing laws of fluid dynamics. The set of partial differential equations associated with the system under study are solved in a geometrical domain divided into small volumes, commonly known as a mesh (or grid). The accuracy and validity of simulation results depends on the choice of the CFD model, the physical features incorporated in the governing equations and the boundary conditions (Ferziger \& Peric, 1996; Tu, Yeoh, \& Liu, 2008).

\subsection{Two-dimensional models}

Almost all the numerical simulations of the hydrodynamic behavior inside electrochemical cells with a RDE have used axisymmetric two-dimensional models, but there are significant differences in the extent of the electrochemical cell volume of the systems reported in literature. The entire cell volume was simulated by Mandin et al. (Mandin, et al., 2004) whereas only a small amount of liquid below a rotating disc ring electrode was considered by Dong et al. (Dong, Santhanagopalan, \& White, 2007). In those works, only the electrode active face is in contact with the fluid. Nevertheless, a common practice of submerge the working electrode into the cell liquid was not considered in those works. Mandin et al. (Mandin, Fabian, \& Lincot, 2006) show the significance of the submerged electrode side wall by means of two-dimensional numerical simulations of an electrochemical cell with a rotating cylinder electrode.

Dong et al. (Dong, Santhanagopalan, \& White, 2008) carried out two-dimensional axisymmetric numerical simulations of a entire electrochemical cell with a RDE, where the electrode is partially submerged into the electrolyte. To include the existence of an air-liquid interface present in actual electrochemical cells, a slip wall was employed as boundary condition for the cell upper wall to represent numerically this interface. The system modeled by Dong et al. (Dong, et al., 2008) is schematically represented in Figure 6. In accordance with these authors, the simulated fluid velocity field and that obtained with the theoretical model proposed by von Kármán (von Kármán, 1921) and Cochran (Cochran, 1934) are in good agreement.

Mandin et al. (Mandin, et al., 2004) also carried out two-dimensional axisymmetric numerical simulations of a entire electrochemical cell with a RDE. The system studied by these authors is schematically represented in Figure 7. Their results were compared with the fluid flow pattern calculated with the analytical expressions obtained by Cochran (Cochran, 1934). These authors found that the velocity profiles calculated with these expressions are in accordance with their numerical simulations only in a narrow region close to the electrode active face. However, apparently these authors only made use of one of the two sets of equations that comprises the solution obtained by Cochran. 


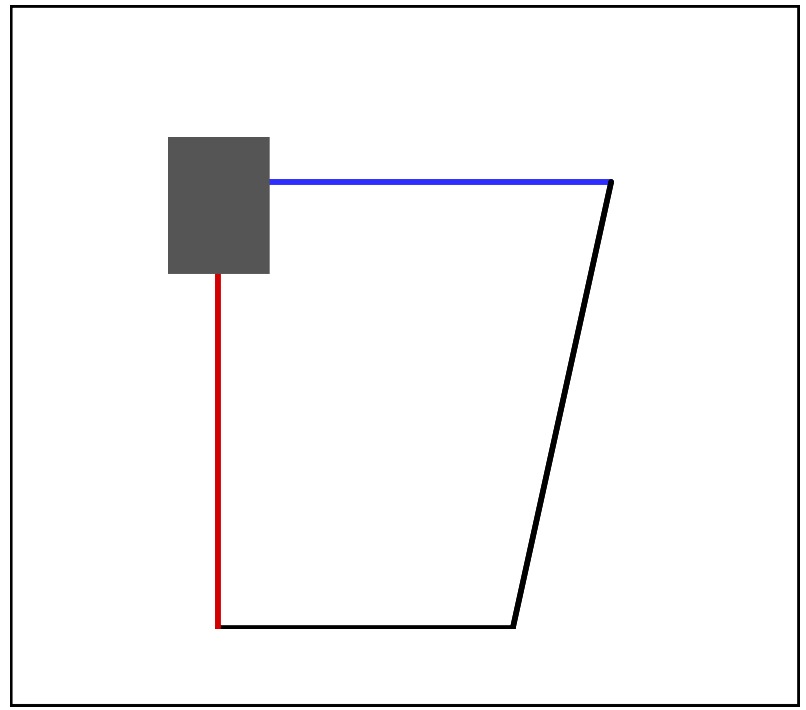

Fig. 6. Schematic representation of the cell simulated by Dong et al. (Dong, et al., 2008). The line in blue represents a slip wall. The line in red represents symmetry axis.

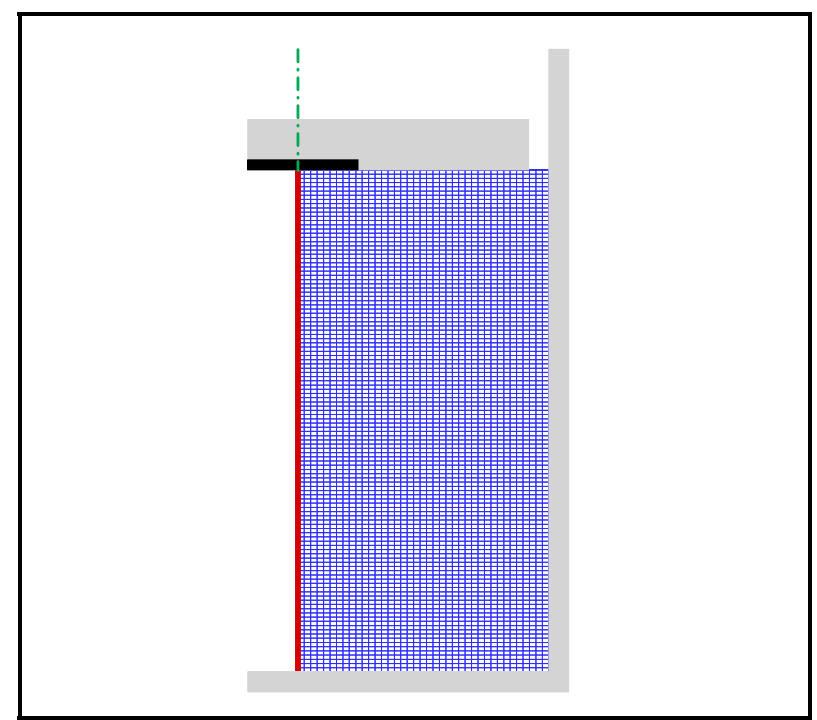

Fig. 7. Schematic representation of the cell simulated by Mandin et al. (Mandin, et al., 2004). The line in red represents symmetry axis. The line in black represents the electroactive zone.

\subsection{Three-dimensional models}

All the two-dimensional mathematical models of electrochemical cells with a RDE assumed that the fluid velocity field is axisymmetric. Nevertheless, the asymmetry of the fluid flow 
was observed in informal experiments reported by Adams (Adams, 1969) (see Figure 4-3 in that work). Despite the asymmetry is evident, no comments regarding this fact were raised; maybe because in accordance with the author, those experiments were done only to illustrate the general behavior of an electrochemical cell with a RDE.

Due to the size and inner geometry of most of the electrochemical cells, scarce measurements of the liquid velocities inside the cell are reported. However, measurements of liquid velocities inside a cell with a rotating disc electrode through the Doppler Laser Anemometry (DLA) technique were performed by Mandin, et al. (Mandin, et al., 2004). In that work, reproducible high amplitude oscillations that increased substantially with the electrode rotation speed were observed. These authors also compared their experimental measurements with the results of a two-dimensional axisymmetric mathematical model, but liquid velocities oscillations were not reproduced.

By using a three-dimensional model, the symmetry constraint can be avoided and therefore, it is possible to reproduce the hydrodynamic behavior of the internal flow of electrochemical cells under more realistic conditions. The correctness of this assumption can be evaluated by comparing the results of the numerical simulations against the physical experiments measurements.

Real, et al. (Real, et al., 2008) characterized the hydrodynamics inside electrochemical cells with several geometric features using three-dimensional models. These authors studied how the fluid flow pattern is affected by the electrode rotation speed, the cell volume, the electrode submergence depth and the distance between the electrode active face and the cell bottom wall. In that work, the authors found that the fluid flow pattern inside the electrochemical cell is not symmetric. Nonetheless, the asymmetry grade strongly depends on the geometrical configuration of the system.

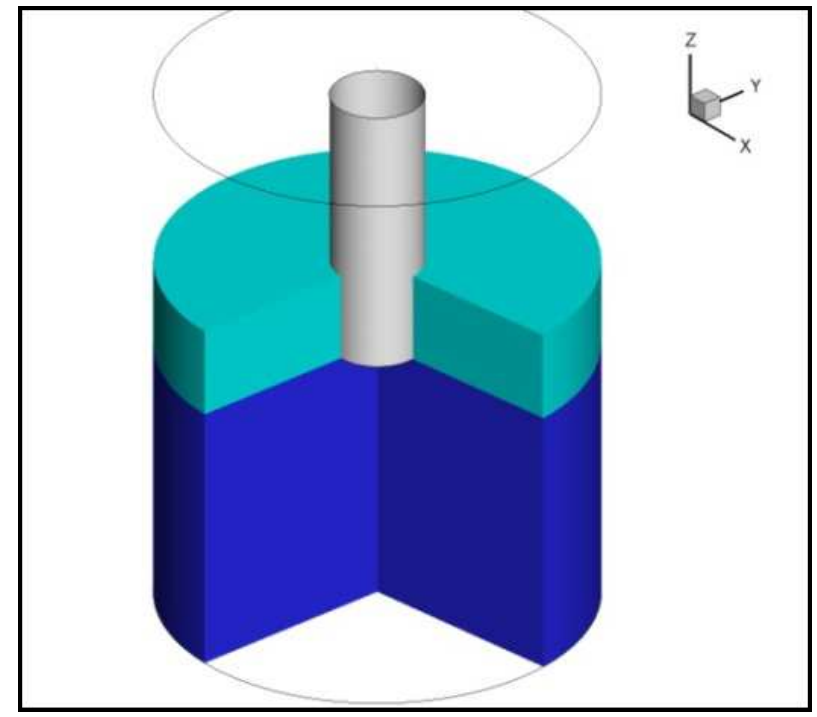

Fig. 8. Example of the biphasic three-dimensional models employed by Gonzalez, et al. (Gonzalez, Real, Hoyos, Miranda, \& Cervantes, 2011), Real-Ramirez, et al. (Real-Ramirez, Miranda-Tello, Hoyos-Reyes, \& Gonzalez-Trejo, 2010) and Real, et al. (Real, et al., 2008). 
In the work of Real, et al. (Real, et al., 2008) only the hydrodynamic behavior of the electrolyte inside the cell was simulated. This means that the effect of the interface electrolyte-air in actual electrochemical cells is neglected. However, the significance of the free surface on the flow pattern inside a stationary cylinder with a rotating bottom has been recognized by several authors (Brøns, Shen, Sørensen, \& Zhu, 2007). By comparing the flow inside two different container geometries, one with a rigid cover and the other with a free surface, significant differences in the resulting behavior were observed experimentally (Spohn, Mory, \& Hopfinger, 1998). This result was reproduced numerically through threedimensional numerical simulations (Serre \& Bontoux, 2007).

The effect of the liquid phase free surface on the flow pattern inside the electrochemical cell with a RDE has been studied recently by Real, et al. (Real, et al., 2008), Real-Ramirez, et al. (Real-Ramirez, et al., 2010) and Gonzalez, et al. (Gonzalez, et al., 2011). These works conducted several three-dimensional unsteady-state numerical simulations using biphasic systems. An example of the biphasic three-dimensional models employed in those works is presented in Figure 8. In this example, the volume occupied by the electrolyte was colored in blue and the electrode was colored in grey. The electrode submergence depth is equal to the electrode external diameter. The distance between the electrode active face and the cell bottom wall is equal to four times the electrode external diameter.

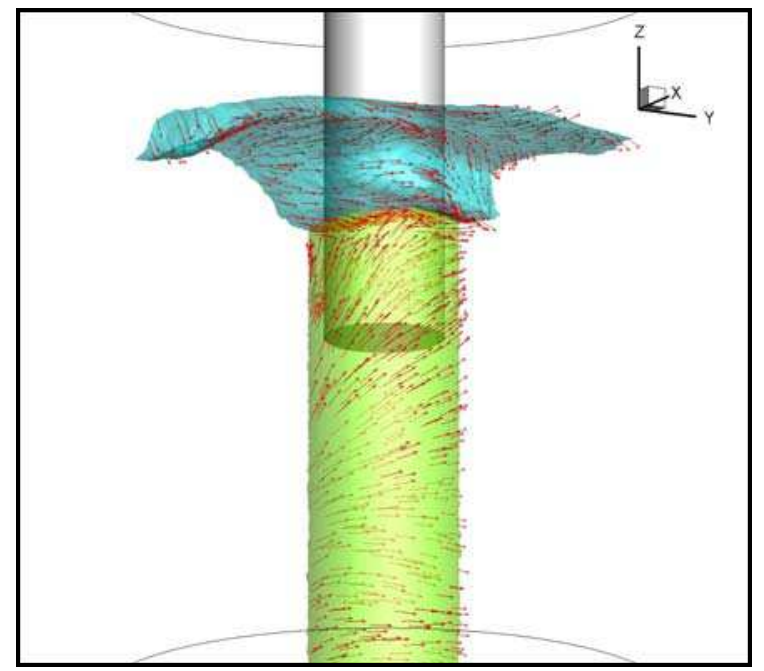

Fig. 9. Liquid velocity vectors near and below the electrode. A section of the liquid freesurface colored in blue is also presented.

Through the biphasic three-dimensional numerical simulations, the authors found that the fluid flow pattern inside the electrochemical cell is not symmetric respect the electrode rotation axis. Figure 9 presents the liquid velocity vectors near and below the electrode. This figure also shows a section of the liquid free-surface, which is colored in blue. A big value for the electrode rotation speed was employed to generate the results shown in Figure 9.

By comparing Figures 1 and 9 it is clear that there is a difference between the behaviors of an actual electrochemical cell and the ideal model stated by von Kármán (von Kármán, 1921). 
The asymmetry of the fluid flow pattern about the axis of rotation of the electrode causes a displacement of the stagnation point on the electrode active face. This displacement is shown in Figure 10.

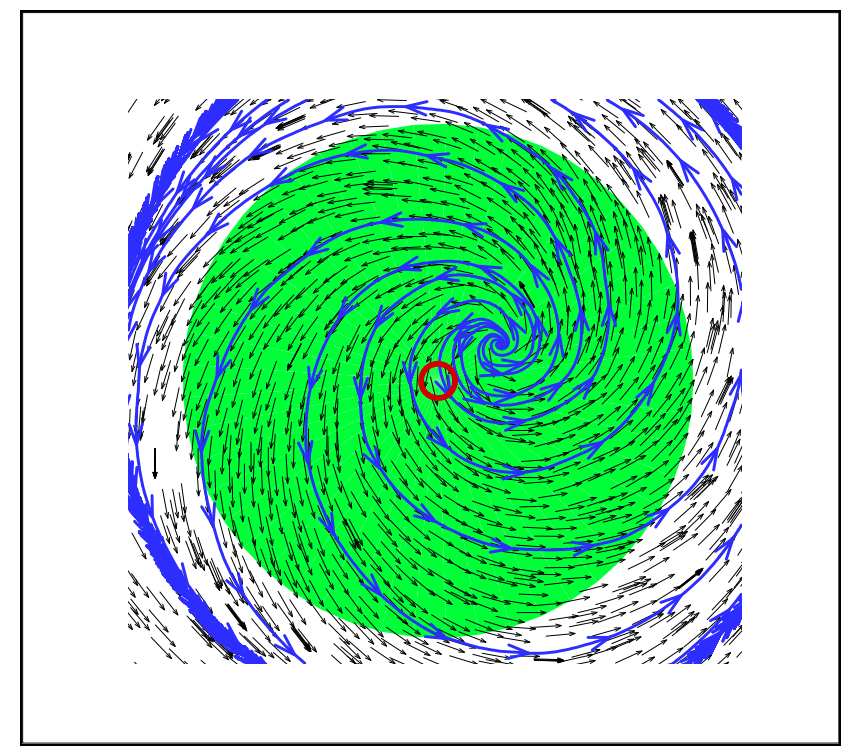

Fig. 10. Displacement of the stagnation point on the electrode active face originated by the asymmetry of the fluid flow pattern. The red circle denotes the centre of the electrode.

The biphasic three-dimensional numerical simulations confirm that the asymmetry grade strongly depends on the geometrical configuration of the system. By analyzing the results of several physical and numerical simulations at different electrode rotation speeds and several cell sizes, those works found that there exist a synergetic effect of the cell internal walls, the submerged electrode side wall and the liquid free surface (Real-Ramirez, et al., 2010). Their numerical simulations showed that the asymmetry of the electrochemical cell flow pattern is intensified by the free surface asymmetry, which depends directly on the electrode rotation speed and the electrode submergence depth (Gonzalez, et al., 2011).

Several fluid stream lines below the electrode for two distinct values of the distance between the electrode active face and the cell bottom wall are shown in Figures 11 and 12. This distance for the cell shown in Figure 11 is small, whereas a large value for the distance between the electrode active face and the cell bottom wall was employed for the cell shown in Figure 12. The same value of the electrode rotation speed was used for the simulations shown in Figures 12 and 13.

Figures 11 and 12 clearly show that the offset from the center of the electrode of the stagnation point depends strongly on the distance between the electrode active face and the cell bottom wall. Based on the results of their numerical simulations, Real-Ramirez, et al. (Real-Ramirez, et al., 2010) stated as rule of thumb that the distance between the electrode active face and the cell bottom wall must be at least three times the electrode external diameter. 


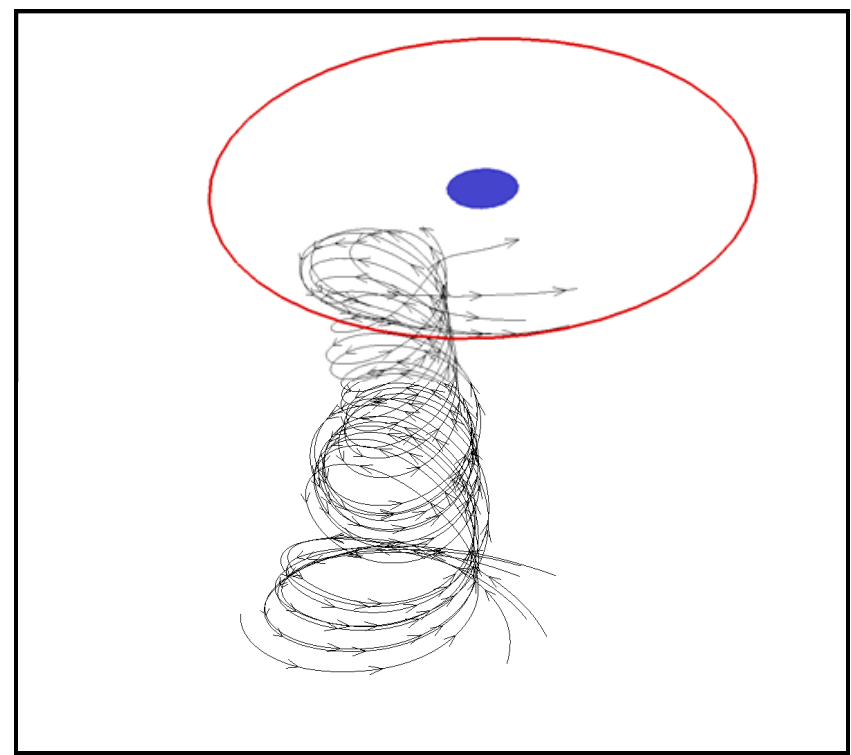

Fig. 11. Fluid stream lines below the electrode when the distance between the electrode active face and the cell bottom wall is small. The blue circle defines the centre of the electrode.

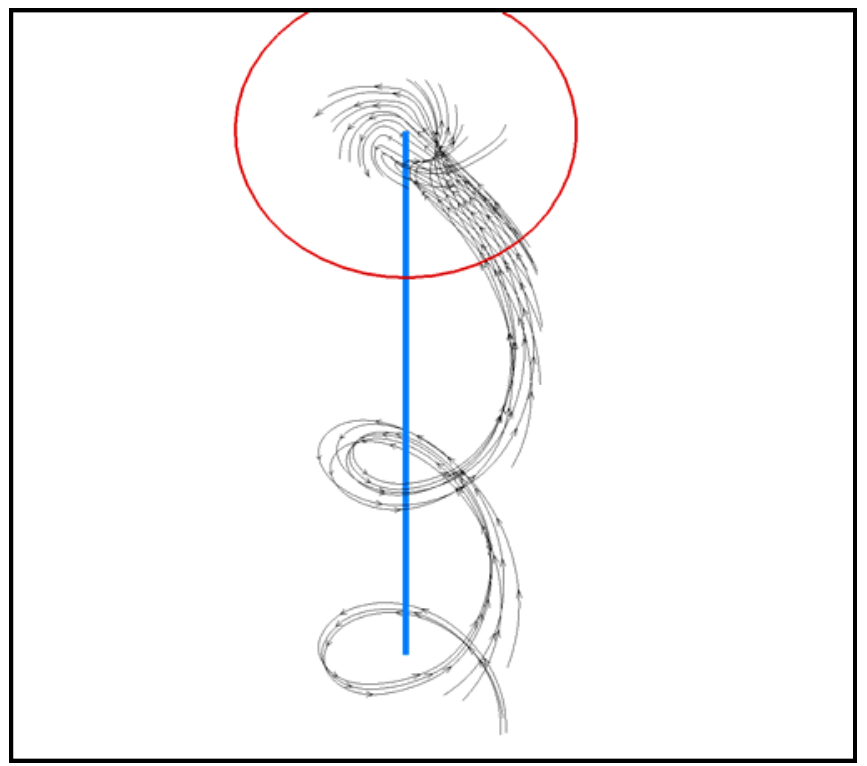

Fig. 12. Fluid stream lines below the electrode when the distance between the electrode active face and the cell bottom wall is large. The blue line coincides with the axis of rotation of the electrode. 


\subsection{Comparison between mathematical and physical experiments}

Based on the results of their numerical simulations and following the functional form of the solutions proposed by Ackroyd (Ackroyd, 1978) and Ariel (Ariel, 1996), Gonzalez, et al. (Gonzalez, et al., 2011) argued that the fluid velocity component orthogonal to the electrode active face decreases almost exponentially with the square root of the electrode rotation speed. Gonzalez, et al. (Gonzalez, et al., 2011) proposed an empirical correction to the Levich equation as follows:

$$
i_{L}=\psi \omega^{1 / 2} e^{-\gamma \omega^{1 / 2}}
$$

where $\psi>0$ has the usual interpretation and $\gamma$ is a constant such that $0<\gamma \ll 1$. The smaller the value of $\gamma$, the closer will be the system to the ideal one. The previous equation implies that $i_{L} \rightarrow 0$ as $\omega^{1 / 2} \rightarrow 0$, nevertheless, the value of $\omega$ cannot be as large as desired because beyond a certain threshold, the Levich equation is no longer valid.

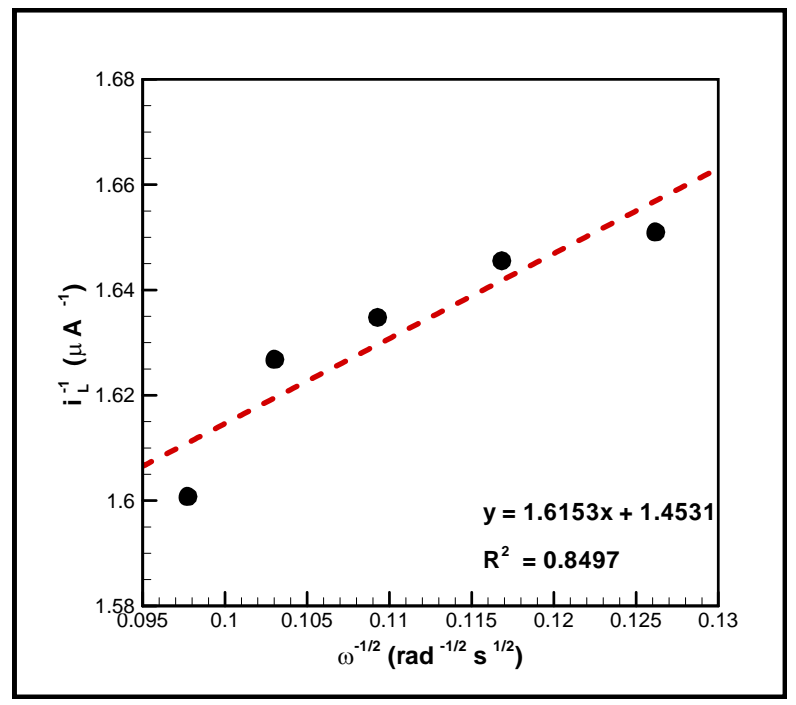

Fig. 13. Koutecky-Levich plot of data reported by Unguresan \& Gligor (Unguresan \& Gligor, 2009) for a concentration of NADH of $1.2 \mathrm{mM}$.

Gonzalez, et al. evaluated the validity of Equation (21) using the experimental results reported by Unguresan \& Gligor (Unguresan \& Gligor, 2009). The experiments correspond with the electrocatalytic NADH oxidation process taking place at graphite electrodes modified with a polymer of phenothiazine formaldehyde at various concentrations of $\mathrm{NADH}$ and for an electrolyte $\mathrm{pH}$ value of 6.0.

Figure 13 shows the traditional Koutecky-Levich plot of data reported by Unguresan \& Gligor for a concentration of NADH of $1.2 \mathrm{mM}$. Figure 14 shows the fitting of the same experimental data by using Equation (21). The equations of the linear adjustment was included these figures. Similar values for the Levich constants $\psi$ are obtained with the model proposed by Gonzalez, et al. (Gonzalez, et al., 2011) and the Koutecky-Levich equation, but the goodness of the fit is significantly improved. 


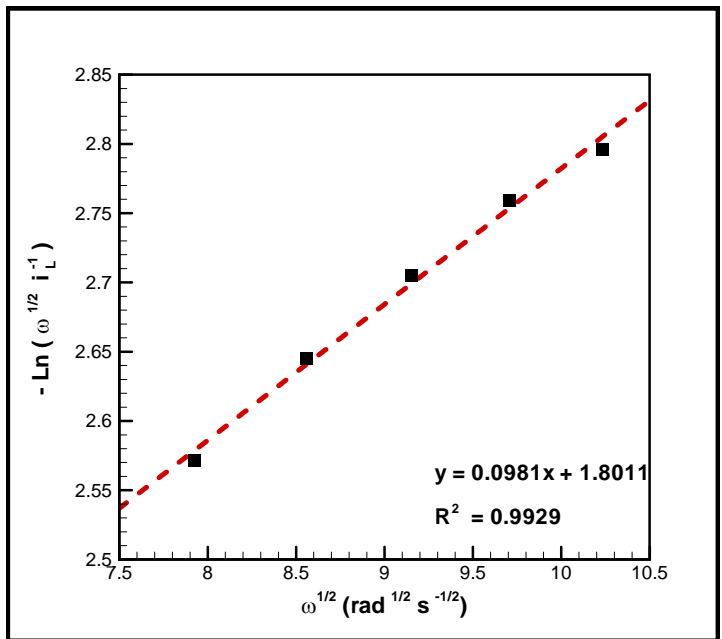

Fig. 14. Fitting of the experimental data reported by Unguresan \& Gligor (Unguresan \& Gligor, 2009) for a concentration of NADH of $1.2 \mathrm{mM}$ by using Equation (21).

The same analysis to that previously described but now for a concentration of NADH of 1.6 $\mathrm{mM}$ is presented in Figures 15 and 16. As in the as in the previous case, the goodness of the fit is superior by using the model proposed by Gonzalez, et al. (Gonzalez, et al., 2011).

\section{Effect of the electrode shape and future trends}

The importance of electrode shape on the behavior of the electrochemical cell has been recognized for a long time. For instance, the inaccuracies caused by the geometry of the electrode are discussed in detail in Section 6 of the Levich work (Levich, 1942).

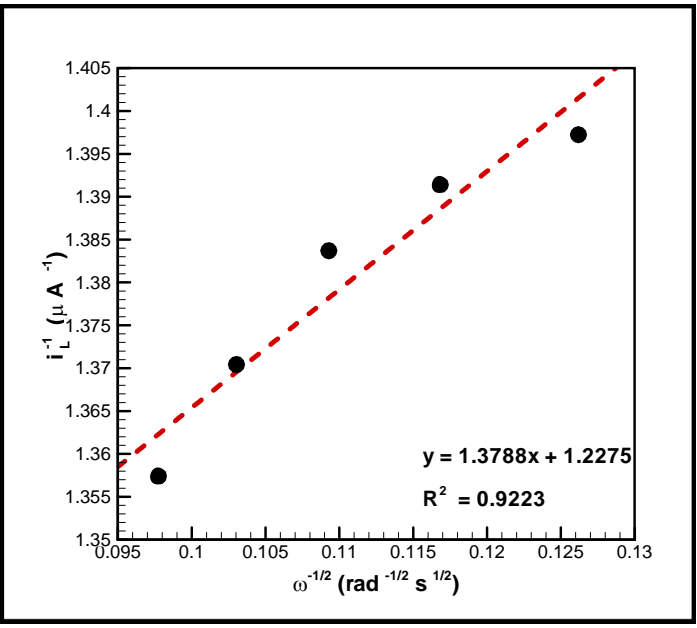

Fig. 15. Koutecky-Levich plot of data reported by Unguresan \& Gligor (Unguresan \& Gligor, 2009) for a concentration of NADH of $1.6 \mathrm{mM}$. 


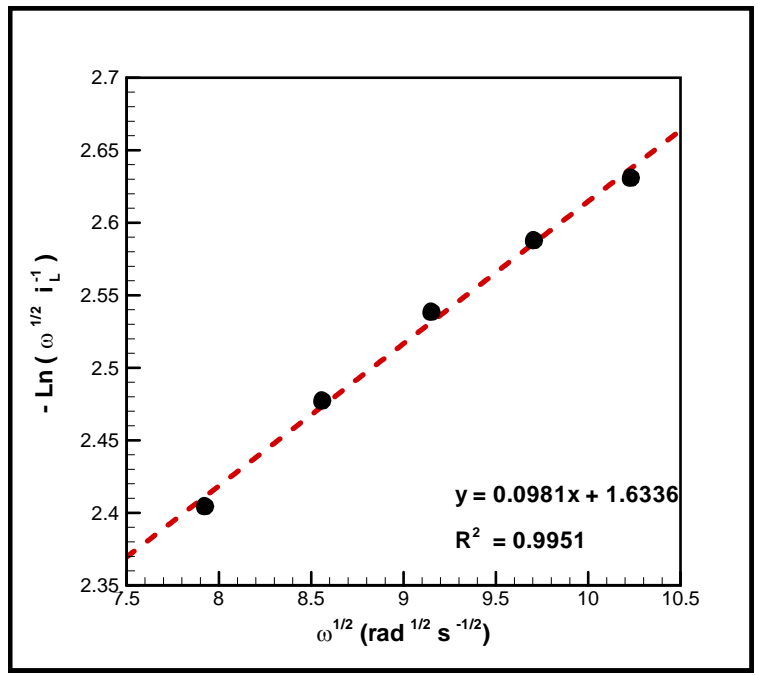

Fig. 16. Fitting of the experimental data reported by Unguresan \& Gligor (Unguresan \& Gligor, 2009) for a concentration of NADH of 1.6 mM by using Equation (21).

By analyzing the results of biphasic three-dimensional numerical simulations of an electrochemical cell with a cylindrical electrode, several authors found that the submerged electrode side wall along with its right angle shape induces that the liquid velocities in the vicinity of the electrode active face were lower than that predicted with the ideal model (Gonzalez, et al., 2011; Real-Ramirez, et al., 2010). To obtain a liquid velocities field as close as possible to the ideal one, those authors suggest using electrodes with rounded border shape.

The cylindrical electrodes are the ones mostly used for the characterization of electrochemical reactions. However, some authors still using bell-shaped electrodes. According to the authors of this chapter, the results of numerical simulations suggest that this type of electrodes may have a better performance than the cylindrical electrodes. Therefore, it is strongly recommended to conduct numerical simulations to characterize the hydrodynamics of an electrochemical cell with a bell-shaped electrode.

\section{Acknowledgements}

The authors are grateful to the support by Universidad Autonoma Metropolitana (Nos.2231207 and 2270303) and to Sistema Nacional de Investigadores (SNI-CONACYT).

\section{References}

Ackroyd, J. A. D. (1978). Steady flow produced by a rotating-disk with either surface suction or injection. Journal of Engineering Mathematics, 12(3), 207-220.

Adams, R. N. (1969). Electrochemistry at solid electrodes. New York,: M. Dekker.

Ariel, P. D. (1996). The flow near a rotating disk: An approximate solution. Journal of Applied Mechanics-Transactions of the ASME, 63(2), 436-438. 
Azim, S., \& Riddiford, A. C. (1962). A new type of rotating disk electrode. Analytical Chemistry, 34(8), 1023-1025

Bircumshaw, L. L., \& Riddiford, A. C. (1952). Transport control in heterogeneous reactions. Quarterly Reviews, Chemical Society, 6(2), 157-185.

Blurton, K. F., \& Riddiford, A. C. (1965). Shapes of practical rotating disc electrodes. Journal of Electroanalytical Chemistry, 10(5-6), 457-464.

Brøns, M., Shen, W. Z., Sørensen, J. N., \& Zhu, W. J. (2007). The influence of imperfections on the flow structure of steady vortex breakdown bubbles. Journal of Fluid Mechanics, 578, 453.

Cochran, W. G. (1934). The flow due to a rotating disc. Proceedings of the Cambridge Philosophical Society, 30, 365-375.

Dong, Q., Santhanagopalan, S., \& White, R. E. (2007). Simulation of the oxygen reduction reaction at an $\mathrm{RDE}$ in $0.5 \mathrm{~m} \mathrm{H} 2 \mathrm{SO} 4$ including an adsorption mechanism. Journal of the Electrochemical Society, 154(9), A888-A899.

Dong, Q., Santhanagopalan, S., \& White, R. E. (2008). A comparison of numerical solutions for the fluid motion generated by a rotating disk electrode. Journal of the Electrochemical Society, 155(9), B963-B968.

Eucken, A. (1932). Die Ermittelung der absoluten Grösse des Diffusionsstromes in Bewegten Elektrolyten. Zeitschrift für Elektrochemie und angewandte physikalische Chemie, 38(6), 341-345.

Ferziger, J. H., \& Peric, M. (1996). Computational methods for fluid dynamics. Berlin ; New York: Springer.

Gonzalez, J., Real, C., Hoyos, L., Miranda, R., \& Cervantes, F. (2011). Characterization of the hydrodynamics inside a practical cell with a rotating disk electrode. Journal of Electroanalytical Chemistry, 651(2), 150-159.

Levich, B. (1942). The theory of concentration polarization. Acta Physicochimica URSS, 17, 257-307.

Mandin, P., Fabian, C., \& Lincot, D. (2006). Importance of the density gradient effects in modelling electro deposition process at a rotating cylinder electrode. Electrochimica Acta, 51(19), 4067-4079.

Mandin, P., Pauporte, T., Fanouillere, P., \& Lincot, D. (2004). Modelling and numerical simulation of hydrodynamical processes in a confined rotating electrode configuration. Journal of Electroanalytical Chemistry, 565(2), 159-173.

Nernst, W. (1904). Theory on the reaction rate in heterogenous systems. Zeitschrift Fur Physikalische Chemie--Stochiometrie Und Verwandtschaftslehre, 47(1), 52-55.

Nernst, W., \& Merriam, E. S. (1905). On the theory of residual current. (According to experiments by Mr. Merriam.). Zeitschrift Fur Physikalische Chemie--Stochiometrie Und Verwandtschaftslehre, 53(2), 235-244.

Prater, K. B., \& Adams, R. N. (1966). A critical evaluation of practical rotated disk electrodes. Analytical Chemistry, 38(1), 153-155.

Real-Ramirez, C. A., Miranda-Tello, R., Hoyos-Reyes, L. F., \& Gonzalez-Trejo, J. I. (2010). Hydrodynamic characterization of an electrochemical cell with rotating disc electrode: A three dimensional biphasic model. International Journal of Chemical Reactor Engineering, 8, 1-37.

Real, C., González, J., Palomar-Pardavé, M., Romero-Romo, M., Aguilar, M., \& Hoyos, L. (2008). A CFD hydrodinamics condition simulation of electrochemical cells with rotating 
electrodes. Paper presented at the International Materials Research Congress, Cancun.

Riddiford, A. C. (1966). The rotating disk system. In P. Delahay (Ed.), Advances in electrochemistry and electrochemical engineering (Vol. 4, pp. 47-116). New York: Wiley.

Serre, E., \& Bontoux, P. (2007). Vortex breakdown in a cylinder with a rotating bottom and a flat stress-free surface. International Journal of Heat and Fluid Flow, 28, 229-248.

Spohn, A., Mory, M., \& Hopfinger, E. J. (1998). Experiments on vortex breakdown in a confined flow generated by a rotating disc. Journal of Fluid Mechanics, 370, 73-99.

Tu, J., Yeoh, G. H., \& Liu, C. (2008). Computational fluid dynamics: A practical approach (1st Ed.) Amsterdam ; Boston: Butterworth-Heinemann.

Unguresan, M. L., \& Gligor, D. M. (2009). Numerical modelling and simulation of KouteckyLevich equation for $\mathrm{NADH}$ electrocatalytic oxidation at graphite electrodes modified with a new polymeric phenothiazine. Indian Journal of Chemistry, Section A, 48A(02), 206-210.

Volgin, V. M., \& Davydov, A. D. (2007). Numerical simulation of steady-state ion transfer to rotating disk electrode: Accuracy and computational efficiency. Journal of Electroanalytical Chemistry, 600(1), 171-179.

von Kármán, T. (1921). Über laminare und turbulente reibung. Zeitschrift für Angewandte Mathematik und Mechanik, 1, 486. 


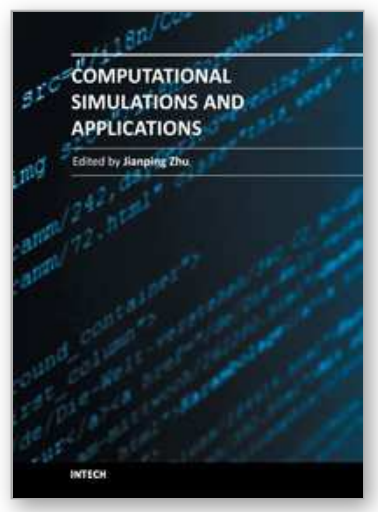

\section{Computational Simulations and Applications}

Edited by Dr. Jianping Zhu

ISBN 978-953-307-430-6

Hard cover, 560 pages

Publisher InTech

Published online 26, October, 2011

Published in print edition October, 2011

The purpose of this book is to introduce researchers and graduate students to a broad range of applications of computational simulations, with a particular emphasis on those involving computational fluid dynamics (CFD) simulations. The book is divided into three parts: Part I covers some basic research topics and development in numerical algorithms for CFD simulations, including Reynolds stress transport modeling, central difference schemes for convection-diffusion equations, and flow simulations involving simple geometries such as a flat plate or a vertical channel. Part II covers a variety of important applications in which CFD simulations play a crucial role, including combustion process and automobile engine design, fluid heat exchange, airborne contaminant dispersion over buildings and atmospheric flow around a re-entry capsule, gas-solid two phase flow in long pipes, free surface flow around a ship hull, and hydrodynamic analysis of electrochemical cells. Part III covers applications of non-CFD based computational simulations, including atmospheric optical communications, climate system simulations, porous media flow, combustion, solidification, and sound field simulations for optimal acoustic effects.

\section{How to reference}

In order to correctly reference this scholarly work, feel free to copy and paste the following:

Cesar Augusto Real-Ramirez and Jesus Isidro Gonzalez-Trejo (2011). Hydrodynamic Analysis of Electrochemical Cells, Computational Simulations and Applications, Dr. Jianping Zhu (Ed.), ISBN: 978-953307-430-6, InTech, Available from: http://www.intechopen.com/books/computational-simulations-andapplications/hydrodynamic-analysis-of-electrochemical-cells

\section{INTECH}

open science | open minds

\section{InTech Europe}

University Campus STeP Ri

Slavka Krautzeka 83/A

51000 Rijeka, Croatia

Phone: +385 (51) 770447

Fax: +385 (51) 686166

www.intechopen.com

\section{InTech China}

Unit 405, Office Block, Hotel Equatorial Shanghai

No.65, Yan An Road (West), Shanghai, 200040, China 中国上海市延安西路65号上海国际贵都大饭店办公楼 405 单元

Phone: +86-21-62489820

Fax: $+86-21-62489821$ 
(C) 2011 The Author(s). Licensee IntechOpen. This is an open access article distributed under the terms of the Creative Commons Attribution 3.0 License, which permits unrestricted use, distribution, and reproduction in any medium, provided the original work is properly cited. 